\title{
Quantitative detection of the tumor-associated antigen large external antigen in colorectal cancer tissues and cells using quantum dot probe
}

\author{
This article was published in the following Dove Press journal: \\ International Journal of Nanomedicine \\ 13 January 2016 \\ Number of times this article has been viewed
}

\section{Shuo Wang \\ Wanming Li \\ Dezheng Yuan \\ Jindan Song \\ Jin Fang}

Department of Cell Biology, Key Laboratory of Cell Biology, Ministry of Public Health, and Key Laboratory of Medical Cell Biology, Ministry of Education, China Medical University, Shenyang, People's Republic of China

Correspondence: Jin Fang Department of Cell Biology, Key Laboratory of Cell Biology, Ministry of Public Health, and Key Laboratory of Medical Cell Biology, Ministry of Education, China Medical University, No 77 Puhe Road, Shenyang North New Area, Shenyang, Liaoning Province, I 10122 , People's Republic of China Tel +862423946749

Email jfang61@netease.com
Abstract: The large external antigen (LEA) is a cell surface glycoprotein that has been proven to be highly expressed in colorectal cancer (CRC) as a tumor-associated antigen. To evaluate and validate the relationship between LEA expression and clinical characteristics of CRC with high efficiency, LEA expression levels were detected in 85 tissue blocks from CRC patients by quantum dot-based immunohistochemistry (QD-IHC) combined with imaging quantitative analysis using quantum dots with a $605 \mathrm{~nm}$ emission wavelength (QD605) conjugated to an ND-1 monoclonal antibody against LEA as a probe. Conventional IHC was performed in parallel for comparison. Both QD-IHC and conventional IHC showed that LEA was specifically expressed in CRC, but not in non-CRC tissues, and high LEA expression was significantly associated with a more advanced T-stage $(P<0.05)$, indicating that LEA is likely to serve as a CRC prognostic marker. Compared with conventional IHC, receiver operating characteristic analysis revealed that QD-IHC possessed higher sensitivity, resulting in an increased positive detection rate of CRC, from $70.1 \%$ to $89.6 \%$. In addition, a simpler operation, objective analysis of results, and excellent repeatability make QD-IHC an attractive alternative to conventional IHC in clinical practice. Furthermore, to explore whether the QD probes can be utilized to quantitatively detect living cells or single cells, quantum dot-based immunocytochemistry (QD-ICC) combined with imaging quantitative analysis was developed to evaluate LEA expression in several CRC cell lines. It was demonstrated that QD-ICC could also predict the correlation between LEA expression and the T-stage characteristics of the cell lines, which was confirmed by flow cytometry. The results of this study indicate that QD-ICC has the potential to noninvasively detect rare circulating tumor cells in clinical samples in real clinical applications.

Keywords: quantum dots, large external antigen, quantum dot-based immunohistochemistry, quantitative analysis, colorectal cancer, quantum dot-based immunocytochemistry

\section{Introduction}

Colorectal cancer (CRC) is the third most common cancer and one of the leading causes of cancer-related deaths worldwide. ${ }^{1,2}$ However, in recent years, the survival rate of CRC patients has significantly increased due to the development of targeted diagnostic and therapeutic approaches based on tumor-associated markers..$^{3-7}$ It is reported that the median progression-free survival time of CRC patients increased from 8.0 to 8.9 months due to the combinatorial usage of cetuximab, a monoclonal antibody (mAb) against epidermal growth factor receptor and Irinotecan with fluorouracil and folinic acid (FOLFIRI), relative to FOLFIRI alone. ${ }^{6}$ Carcinoembryonic antigen (CEA) was recently found to be a potential early marker for CRC due its ability to be detected 17-24 months prior to clinical diagnosis. ${ }^{7}$ Therefore, effective marker detection, along with quantitative 
evaluation of their presence, is critical for accurate early diagnosis, recurrence prediction, and therapy guidance.

ND-1 is a mAb that is generated with hybridoma technology using the CRC cell line, CL187 as an immunogen, with its target-binding molecule as a cell surface glycoprotein named large external antigen (LEA). A previous study demonstrated that LEA is a potential tumor-associated antigen and is preferentially expressed to varying degrees in CRC tissues, with weak or no expression in tissues from noncolorectal tumors, normal adult, and normal fetus. ${ }^{8}$ Its specificity to CRC was proven to be better than that of commercial CEA. ${ }^{9}$ Additionally, LEA can be detected in the serum and ascites of CRC patients, offering a convenient clinical access. ${ }^{8}$ All of these results indicate that LEA may serve as a valuable diagnostic marker for CRC. Therefore, it is necessary to quantitatively evaluate LEA expression in CRC using effective detection approaches and to verify its role during $\mathrm{CRC}$ tumorigenesis and development.

Currently, conventional immunohistochemistry (IHC) is the most widely used technology to evaluate tumor protein marker expression in clinical specimens, and further expression quantitation can be performed with optical intensity analysis. ${ }^{10,11}$ However, several disadvantages of this technology limit its application. First, conventional IHC is a multistep staining procedure and therefore any errors from individual steps would unavoidably accumulate in the final results, leading to low reproducibility and difficult method standardization. Second, the assessment of results of conventional IHC is strongly dependent on the chromogenic reaction intensity, which varies with different reaction times. ${ }^{12}$ As a result, false-positive rates are high, and there are alternative subjective interpretations of the same result due to operator variation, influencing the accuracy of the results. Lastly, the relatively low detection sensitivity cannot meet the needs of clinical practice. ${ }^{13-15}$

Quantum dots (QDs) are fluorescent 2-10 nm nanocrystals with unique optical characteristics, such as superior signal brightness, resistance to photobleaching, and high sensitivity. ${ }^{16,17}$ QDs can be conjugated to different biomolecules, such as antibodies ${ }^{18,19}$ and aptamers, ${ }^{20,21}$ via covalent or noncovalent coupling 22,23 to serve as QD probes for specific molecular imaging, diagnostic immunoassays, and targeted drug delivery. ${ }^{24,25}$ Based on the advantages of QD probes, many researchers have focused on developing QDbased immunohistochemistry (QD-IHC) to investigate the expression levels of biomarkers in tumor tissues, which has generated detection results similar to conventional IHC. ${ }^{26-28}$ More importantly, QD-IHC is proven to be superior to conventional IHC in many aspects. ${ }^{29,30} \mathrm{QD}-\mathrm{IHC}$ possesses higher sensitivity leading to an increased positive detection rate compared to conventional IHC. Using QD-IHC, Ruan et $\mathrm{al}^{31}$ detected prostate stem cell antigen expression levels in human prostate cancer tissue, achieving a higher positive rate than with conventional IHC (76.3\% vs $70.0 \%)$. In addition, fluorescent signals of QD-IHC are extremely stable due to the high photobleaching resistance of QDs, which makes it well suited for the repeated examination of clinical tissue sections. In the study by Chen et $\mathrm{al},{ }^{32}$ the fluorescent intensity of QD probes labeled in breast cancer tissue sections did not significantly change after 9 days, nor even after 75 days in some cases. All of these attributes, along with its less subjective operator interference, make QD-IHC suitable for the quantitative analysis of tumor markers. To quantify LEA expression levels in CRC tissues, and therefore evaluate the clinical significance of LEA as a predicted marker, we developed QD-IHC combined with imaging quantitative analysis for detection of 85 tissue specimens from patients with CRC. The results showed that QD-IHC had a higher sensitivity, which resulted in a higher positive detection rate than conventional IHC. Statistical analysis revealed that LEA expression was correlated with T-stage, indicating LEA could serve as a prognostic tool for CRC.

At present, most reports focus on the usage of QD probes for evaluating protein marker expression in tumor tissues, but not in living cells, however, with the proposed employment of individualized treatment strategies and precise medicine, there is an urgent need for the development of noninvasive and more convenient detection methods to monitor therapeutic response and predict disease progression, for which, circulating tumor cells (CTCs) from peripheral blood are considered to be one of the most promising targets. ${ }^{33}$ Accordingly, we established a QD probe-based immunocytochemistry (QD-ICC) approach to detect LEA expression in CRC living cells in combination with imaging quantitative analysis. Meanwhile, flow cytometry (FCM), an applicable quantitative technology, was used to confirm the efficiency of the method developed herein.

\section{Materials and methods Cell culture and tissue specimens}

Human CRC cell lines, Colo205, CL187, and HT29; the human cervical carcinoma cell line, $\mathrm{HeLa}$; and the $\mathrm{IC}_{2}$ cell line were used in this study. The colo205 and HeLa cells were purchased from the Chinese Academy of Sciences (Shanghai, China). The CL187 and HT29 cells were purchased from American Type Culture Collection (ATCC; Manassas, VA, USA). The study was approved by the Ethics Committee of China Medical University. The $\mathrm{IC}_{2}$ cell line 
was created with hybridoma technology using CL187 cells as an immunogen, which were able to secrete ND-1 mAb. ${ }^{8}$ CL187 cells were cultured in Dulbecco's Modified Eagle's Medium (Thermo Fisher, Grand Island, NY, USA). Colo205, HT29, HeLa, and $\mathrm{IC}_{2}$ cells were maintained in Roswell Park Memorial Institute 1640 (Thermo Fisher) medium. The culture media were supplemented with $10 \%$ fetal bovine serum (Sigma-Aldrich, St Louis, MO, USA) and 100 units/ $\mathrm{mL}$ penicillin-streptomycin (Thermo Fisher). All of the cells were grown in an atmosphere of $5 \% \mathrm{CO}_{2}$ at $37^{\circ} \mathrm{C}$.

Formalin-fixed, paraffin-embedded tissue blocks, including 77 cases of CRC and eight cases of adjacent noncancerous colon tissues, were obtained from archives of First Affiliated Hospital of China Medical University from October 2007 to June 2011. Written informed consent was obtained from all patients and the study was approved by the Ethics Committee of China Medical University.

\section{Production and immune-activity identification of ND-I mAb}

Six- to eight-week-old female BALB/c mice were purchased from the Experimental Animal Center of China Medical University. To obtain ND-1 mAb, $0.2 \mathrm{~mL}$ of an $\mathrm{IC}_{2}$ cell suspension containing $\sim 2 \times 10^{5}$ cells was injected intraperitoneally into the pristane-primed mice. After 10-14 days, the mouse ascites fluids were collected, from which ND-1 was purified by affinity chromatography using HiTrap Protein G columns (GE Healthcare, Bio-Sciences, Boston, MA, USA) according to manufacturer's protocols. The purity of ND-1 was analyzed by electrophoresis on a $12 \%$ sodium dodecyl sulfate gel, and then stained with 0.1\% Coomassie Brilliant Blue R250 solution (Sigma-Aldrich). The bands on the gel were subjected to gray scanning and quantified using Bandscan software (Glyko, Novato, CA, USA). The specific recognition by ND-1 of CL187 cells expressing LEA was determined using immunofluorescence technology. Briefly, CL187 cells were cultured on a cover slip at a density of $1 \times 10^{6}$ cells $/ \mathrm{mL}$. The cells were first incubated with primary antibody ND-1, followed by secondary antibody, fluorescein isothiocyanatelabeled goat antimouse IgG (Zhongshan Goldbridge Biotechnology, Beijing, China). Subsequently, fluorescent images were observed under a fluorescent microscope (Axiovert 200 M; Carl Zeiss Meditec AG, Jena, Germany).

\section{Preparation and specificity analysis of QD probes}

Purified ND-1 was chemically biotinylated by mixing $N$-hydroxysuccinimidobiotin (Sigma-Aldrich) and ND-1 at a molar ratio of $25: 1$ on a rotating shaker at $50 \mathrm{rpm}$ for 4 hours at room temperature (RT). ND-1-biotin was obtained after redundant $N$-hydroxysuccinimidobiotin was removed using ultrafiltration (30,000 MWCO; Merck Millipore, Billerica, MA, USA). ND-1-conjugated QD probes were generated by attaching QD-conjugated streptavidin with a $605 \mathrm{~nm}$ emission wavelength (QD605-SA; Wuhan Jiayuan Quantum Dots Co., Ltd., Wuhan, China) to ND-1-biotin.

To investigate the specific binding ability of the QD probes to LEA expressed on CL187 cell membranes, a QD-ICC assay was adopted. CL187 cells cultured on cover slips at a density of $1 \times 10^{6}$ cells $/ \mathrm{mL}$ for 24 hours were fixed with 4\% paraformaldehyde (PA) for 15 minutes and washed three times with phosphate-buffered saline (PBS). After blocking with $1 \%$ bovine serum albumin at RT for 30 minutes, followed by three washes with PBS, the cells were incubated with ND-1-biotin at a concentration of $25.0 \mu \mathrm{g} / \mathrm{mL}$ at $37^{\circ} \mathrm{C}$ for 1 hour, washed three times in PBS, and incubated with QD605-SA at a concentration of $5.0 \mathrm{nmol} / \mathrm{L}$ for 15 minutes. Instead of ND-1-biotin, PBS and IgG-biotin (Zhongshan Goldbridge Biotechnology) were used as blank control and negative control, respectively. The nuclei were counterstained with 4,6-diamidino-2-phenylindole dihydrochloride (Sigma-Aldrich) for 5 minutes at RT. After washing three times with PBS, the fluorescent signals were examined under a laser scanning confocal microscope (LSM510; Carl Zeiss Meditec AG) with a $488 \mathrm{~nm}$ argon laser.

To further validate the specificity of the QD probes, a competitive assay between nonbiotinylated ND-1 and ND-1biotin was performed. CL187 cells cultured on cover slips were fixed with $4 \% \mathrm{PA}$, and then treated with increasing concentrations of the nonbiotinylated ND-1 $(6.25,12.5,25.0$, and $50.0 \mu \mathrm{g} / \mathrm{mL}$ ) at $37^{\circ} \mathrm{C}$ for 1 hour. Subsequently, the cells were incubated with ND-1-biotin $(25.0 \mu \mathrm{g} / \mathrm{mL})$ followed by QD605-SA $(5.0 \mathrm{nmol} / \mathrm{L})$. The fluorescent images were captured with LSM510 and semi-quantitative analysis was performed by LSM510 analysis software.

\section{Detection of LEA expression in CRC cell lines using the QD-ICC assay}

To demonstrate the capability of the QD probes to quantitatively evaluate distinct LEA expression levels in various CRC cells, three types of CRC cell lines, Colo205, CL187, and HT29, were chosen for quantitative assay, and HeLa cells were used as a negative control. The method developed herein of QD-ICC combined with imaging quantitative analysis was used to detect LEA expression levels. Briefly, cells were first grown on cover slips overnight before fixation with $4 \%$ PA, and then incubated with ND-1-biotin followed by QD605-SA as above. Finally, images were taken under the fluorescent 
microscope. For quantitative assay, five independent areas were imaged per sample and their fluorescence intensity was measured by an image analysis system (MetaMorph software; UIC, Downingtown, PA, USA). The average of five densities was used as the quantitation of each sample.

\section{Quantitative detection of LEA expression in CRC cell lines with FCM}

To confirm the results for LEA expression analysis with QD-ICC assays, FCM analysis was performed. Colo205, CL187, HT29, and HeLa cells were seeded separately in six-well plates at a density of $1 \times 10^{5}$ cells/well and cultured overnight. After trypsinization and centrifugation, the cells were fixed in $70 \%$ ethanol at $4^{\circ} \mathrm{C}$ for 30 minutes, and then incubated with ND-1-biotin and QD605-SA sequentially. Lastly, the cells were suspended in PBS and analyzed by FCM (FACSAria; Becton-Dickinson, San Jose, CA, USA). A blank control for each cell line was performed by replacing ND-1-biotin with PBS. Each experiment was performed in triplicate.

\section{Detection of LEA expression in CRC specimens using QD-IHC and conventional IHC}

Tissue blocks were cut into $4 \mu \mathrm{m}$ consecutive sections for QD-IHC and conventional IHC staining. The sections were deparaffinized and rehydrated, and antigen retrieval was performed using pressure heating in citrate buffer. For QD-IHC staining, the sections were blocked with 2\% bovine serum albumin and incubated with ND-1-biotin overnight at $4^{\circ} \mathrm{C}$ and then QD605-SA for 15 minutes at RT. Finally, the sections were mounted with glycerol mounting medium. The fluorescent images were taken with the fluorescent microscope. For conventional IHC staining, the sections were blocked with $10 \%$ goat serum in PBS and incubated sequentially with the primary antibody ND-1, overnight at $4^{\circ} \mathrm{C}$ and the secondary antibody, biotinylated goat antimouse IgG, for 15 minutes at RT. Finally, the streptavidin-horseradish peroxidase (Kit-9720, Ultrasensitive S-P; Fuzhou Maixin Biotech. Co., Ltd., Fuzhou, China) was incubated with the sections for 15 minutes at RT. Chromogenic reaction was performed with a DAB Kit (Fuzhou Maixin Biotech. Co., Ltd.). Images were taken with the optical microscope.

\section{Scoring method}

For quantitative detection of LEA expression in tissue sections, different scoring methods were used for QD-IHC and conventional IHC staining. For QD-IHC staining, the fluorescence intensity of images was first read by the MetaMorph software and then scored according to the intensity values. Three randomly selected fields for each sample were imaged and measured, and the average of three intensity values was reported as the quantitation of each sample. On the basis of quantitative results, the degree of LEA expression was quantified as follows: 0 , negative expression; $1+$, weak expression; $2+$, moderate expression; and 3+, strong expression.

For conventional IHC staining, the percentage of positive cells and the staining intensity were evaluated separately. The percentage of positive cells was scored as follows: 1 , positive cells $\leq 10 \% ; 2,11 \%-50 \% ; 3,51 \%-80 \% ; 4, \geq 81 \%$. The staining intensity was scored as follows: 0 , no staining; 1, pale yellow; 2, brownish-yellow; 3 , tan. The product of multiplication of the two values was the final score of the image. Three independent areas were saved as images and the staining score of each section was calculated from the mean value of the three areas. Accordingly, the degree of LEA expression was quantified as follows: 0, negative expression (0 score); 1+, weak expression (1-3 scores); $2+$, moderate expression (4-8 scores); and $3+$, strong expression (9-12 scores).

The scores of QD-IHC and conventional IHC were calculated by two independent observers. In cases of disagreement, the scores were determined by negotiation.

\section{Statistical analysis}

Student's $t$-test was used to investigate the differences in LEA expression between different cell lines determined by both QD-ICC assay and FCM. A paired $t$-test was used to compare the results between the QD-ICC assay and FCM. Spearman's correlation analysis and the chi-square test were applied to assess the correlation between LEA expression and major pathological characteristics. Receiver operating characteristic (ROC) analysis was conducted to compare the sensitivity and specificity of QD-IHC and conventional IHC. $P<0.05$ was considered significant. Statistical analysis was performed with IBM SPSS 20.0 (IBM Corporation, Armonk, NY, USA).

\section{Results \\ Preparation and specificity analysis of QD probes}

To obtain the ND-1 mAb, ND-1-secreting $\mathrm{IC}_{2}$ cells were injected intraperitoneally into $\mathrm{BALB} / \mathrm{c}$ mice for the production of ascites fluids, from which ND-1 was purified with affinity chromatography. Sodium dodecyl sulfate polyacrylamide gel electrophoresis showed a purity of more 


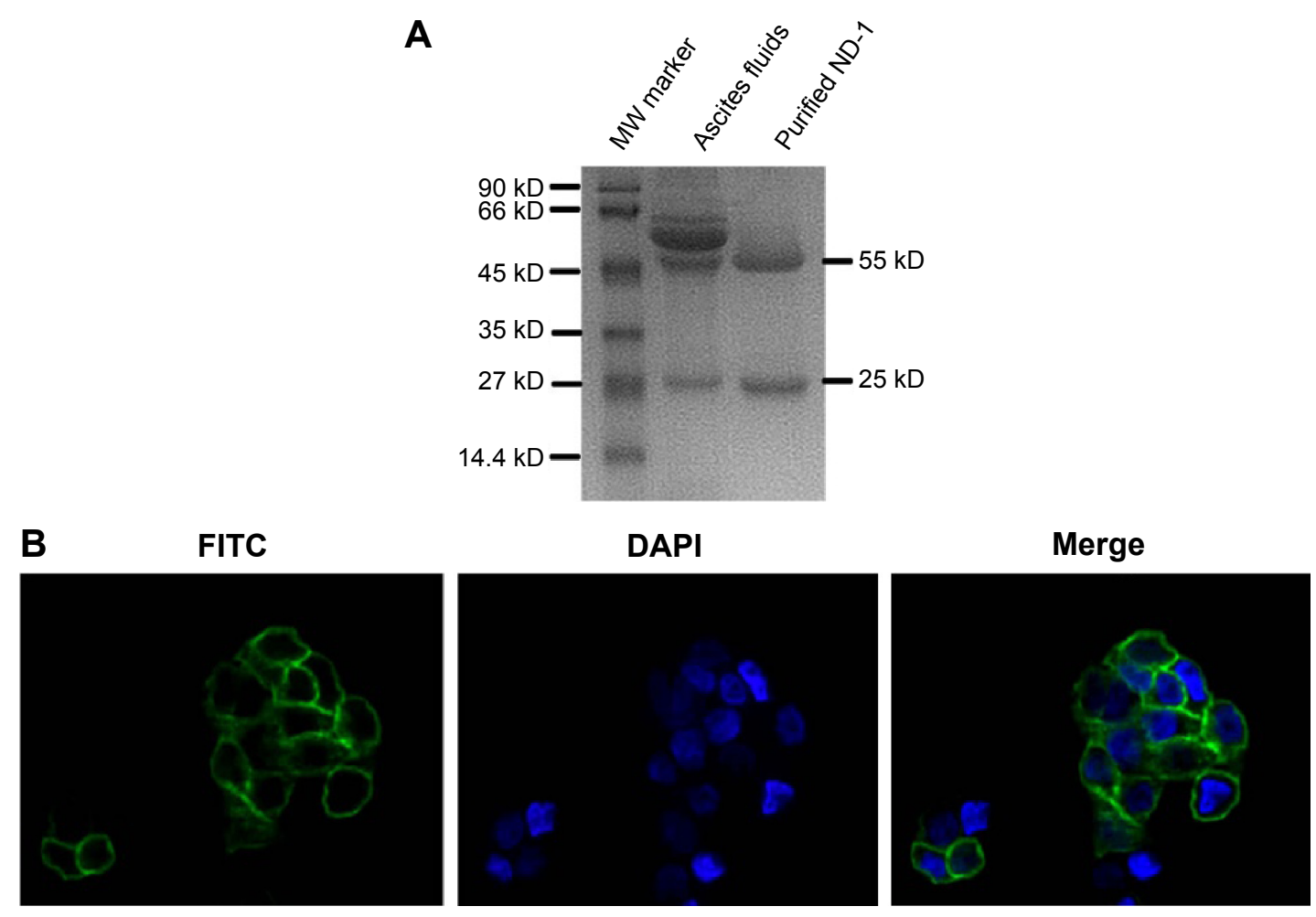

Figure I Purity analysis and immunological activity assay of purified ND-I.

Notes: (A) ND-I was purified from mouse ascites fluids and subjected to SDS-PAGE analysis. (B) Immunological activity of purified ND-I was assayed by immunofluorescence technology. CLI87 cells were first incubated with ND-I, followed by FITC-labeled goat antimouse IgG. The nuclei were stained with DAPI. (Magnification, $\times 600$.) Abbreviations: MW, molecular weight; kD, kilodalton; FITC, fluorescein isothiocyanate; DAPI, 4,6-diamidino-2-phenylindole dihydrochloride; SDS-PAGE, sodium dodecyl sulfate polyacrylamide gel electrophoresis.

than 95\% quantified by Bandscan software (Figure 1A). Under immunofluorescence, the surface of CL187 cells displayed obvious green fluorescence (Figure 1B), indicating that ND-1 possessed strong immune-binding activity to LEA-expressing cells.

To prepare ND-1-conjugated QD probes, purified ND-1 was biotinylated. Upon the conjugation of ND-1-biotin to QD605-SA, the functional QD probes were generated. The binding specificity of QD probes was determined using the LEA-expressing cell line CL187 by QD-ICC assay. As shown in Figure 2A, there was a strong red fluorescence on the CL187 cell membrane. By contrast, no notable fluorescence was observed when the cells were instead incubated with either PBS or IgG-biotin. To further confirm the binding specificity of QD probes, the competitive assay between nonbiotinylated ND-1 and ND-1-biotin was performed. Increasing concentrations of nonbiotinylated ND-1 were individually incubated with CL187 cells followed by incubation with QD probes. Figure 2B shows that as the concentration of nonbiotinylated ND-1 increased, the red fluorescence on the cell membrane of target cells was decreased accordingly. The results indicated that the binding of QD probes to target cells could be blocked by nonbiotinylated ND-1 and therefore the detectable red fluorescence on the cell surface was attributed to the specific recognition by ND-1 in the QD probe of LEA. Semi-quantitative analysis with LSM510 software provided a consistent result.

\section{Detection of LEA expression in CRC cell lines using QD-ICC assay}

To explore whether the QD probes can be utilized to quantitatively detect LEA expression at the cellular level, the QD-ICC method was combined with imaging quantitative analysis. Several cell lines including three CRC cell lines, Colo205, CL187, and HT29, and HeLa cells, which do not express LEA on their membranes, were subjected to the method. The resultant images are shown in Figure 3A. Except for LEAnegative HeLa cells, all types of CRC cells displayed visible fluorescence signals of varying intensities. For quantitative evaluation, five independent images were randomly taken for each sample and the fluorescence intensity of each image was quantified by the image analysis system. The results are displayed in Figure 3B with the four cell lines ordered 
A
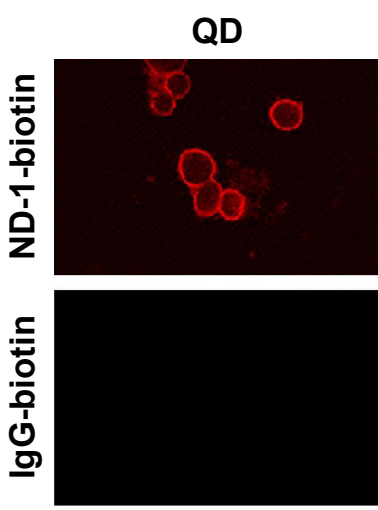

$\boldsymbol{m}$

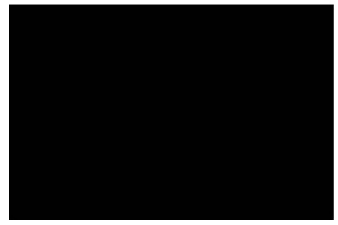

DAPI
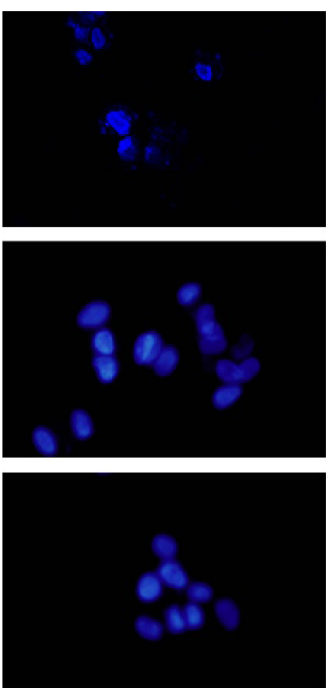

Merge
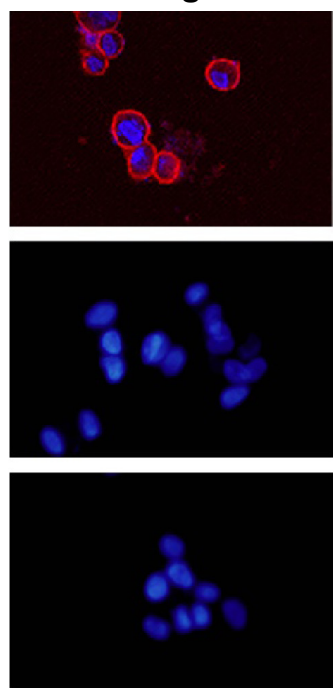

B

$6.25 \mu \mathrm{g} / \mathrm{mL}$

$12.5 \mu \mathrm{g} / \mathrm{mL}$

$25.0 \mu \mathrm{g} / \mathrm{mL}$

$50.0 \mu \mathrm{g} / \mathrm{mL}$
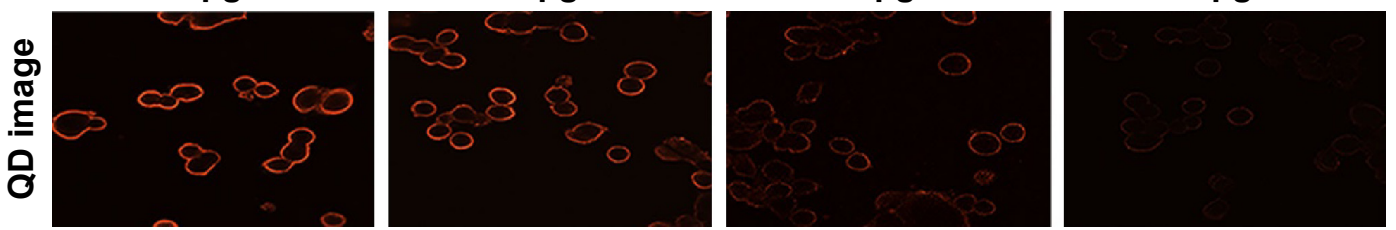

ल
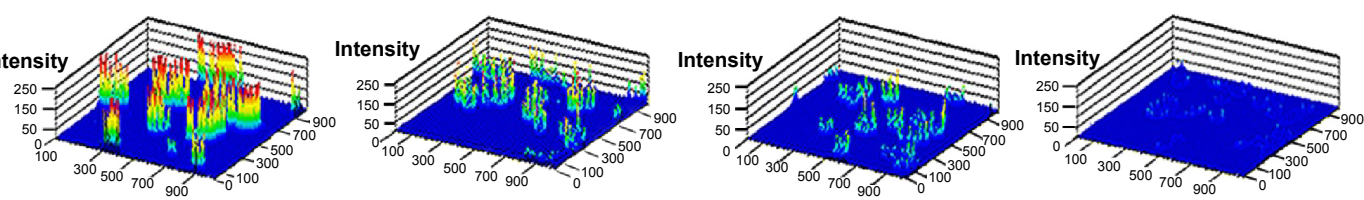

Figure 2 Specificity analysis of ND-I-conjugated QD probes.

Notes: (A) Immunofluorescence analysis of the QD probes specificity. LEA-expressing CLI87 cells were labeled with ND-I-biotin and QD605-SA sequentially, and IgG-biotin and PBS were used as controls. (B) Specific competitive assay. Before incubation with ND-I-biotin and QD605-SA, CLI87 cells were treated with increasing concentrations of nonbiotinylated ND-I $(6.25,12.5,25.0$, and $50.0 \mu \mathrm{g} / \mathrm{mL})$ for competitive binding. The fluorescence images were taken (upper row) and changes in intensity were quantified with LSM5I0 software (Carl Zeiss Meditec AG, Jena, Germany; bottom row). (Magnification, $\times 400$.)

Abbreviations: LEA, large external antigen; QD, quantum dot; QD605-SA, quantum dot-conjugated streptavidin with a $605 \mathrm{~nm}$ emission wavelength; DAPI, 4,6-diamidino2-phenylindole dihydrochloride; PBS, phosphate-buffered saline.
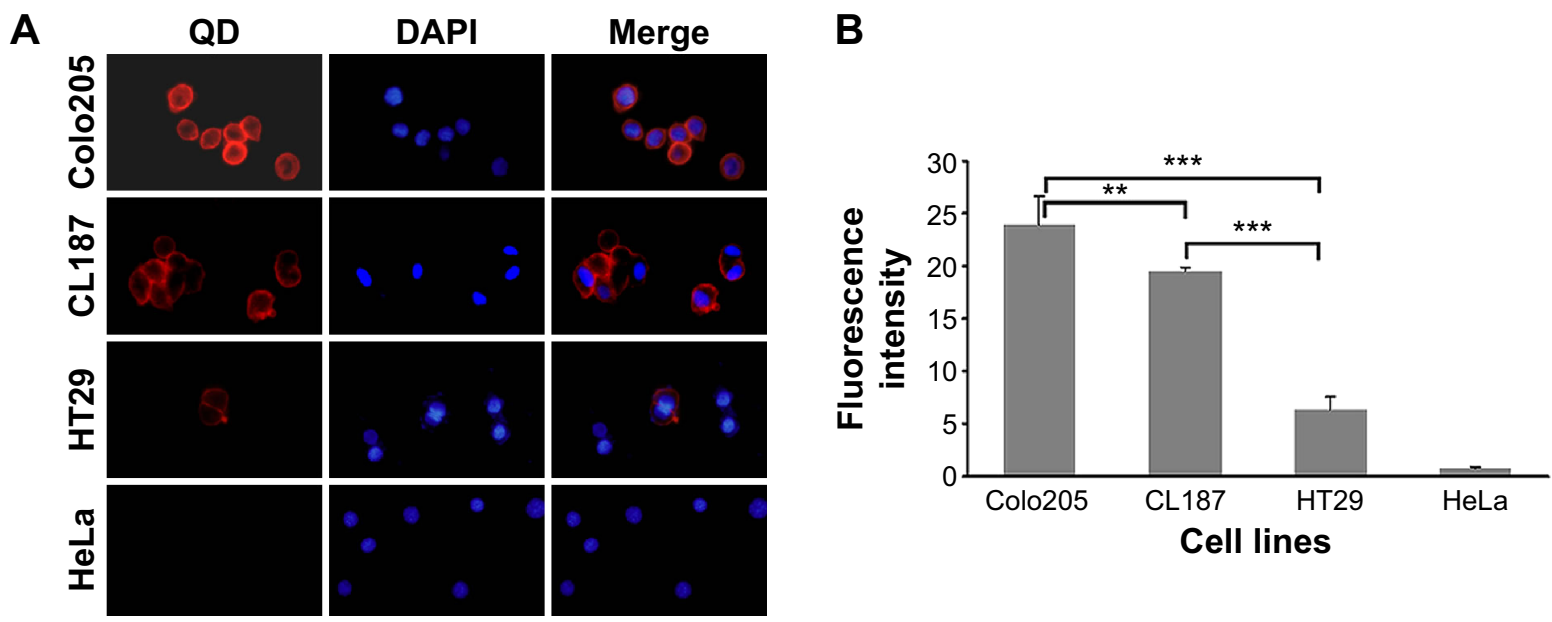

Figure 3 QD-ICC combined with imaging quantitative analysis of LEA expression in various cell lines.

Notes: (A) QD-ICC images taken by fluorescence microscopy. Colo205, CLI87, HT29, and HeLa cells were separately incubated with ND-I-biotin followed by QD605-SA. The nuclei were stained with DAPI. (Magnification, $\times 400$.) (B) Quantitative results based on QD-ICC. Five images of each cell type were taken and the fluorescence intensities were quantified. Data were presented as the mean \pm standard deviation. $* * P<0.01$, $* * * P<0.00 \mathrm{I}$.

Abbreviations: QD-ICC, QD-based immunocytochemistry; LEA, large external antigen; QD, quantum dot; QD605-SA, quantum dot-conjugated streptavidin with a 605 nm emission wavelength; DAPI, 4,6-diamidino-2-phenylindole dihydrochloride. 
according to their fluorescence intensity values: Colo205 $(23.87 \pm 2.81)>\operatorname{CL} 187(19.54 \pm 0.28)>\operatorname{HT} 29(6.35 \pm 1.27)>$ $\operatorname{HeLa}(0.82 \pm 0.13)$.

To verify whether the QD-ICC combined with imaging quantitative analysis could accurately quantify LEA expression levels on cells, FCM, a widely applicable quantitative technique, was employed for comparative detection using QD probes. Fluorescence intensities of four cell lines labeled with QD probes were measured by FCM. The relative fluorescence intensity of the cells is shown in Figure 4A and mean fluorescence intensity values (Figure 4B) were Colo205 $(447.7 \pm 16.7)>\operatorname{CL} 187(379.0 \pm 6.7)>$ HT29 $(96.0 \pm 5.5)>$ HeLa (21.0 \pm 1.2$)$. These results were in accordance with those obtained by the QD-ICC combined with imaging quantitative analysis. A paired $t$-test analysis revealed a good mutual agreement between the two methods ( $\mathrm{K}=0.972, P=0.000)$.

\section{A}
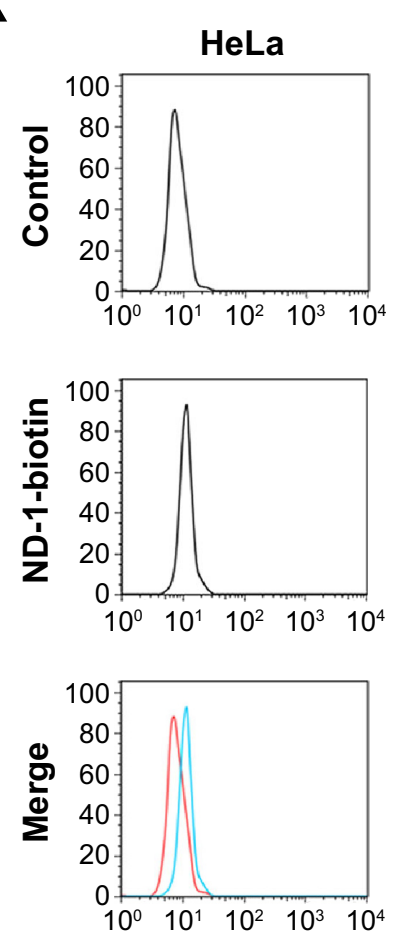

- Control $=$ ND-1-biotin
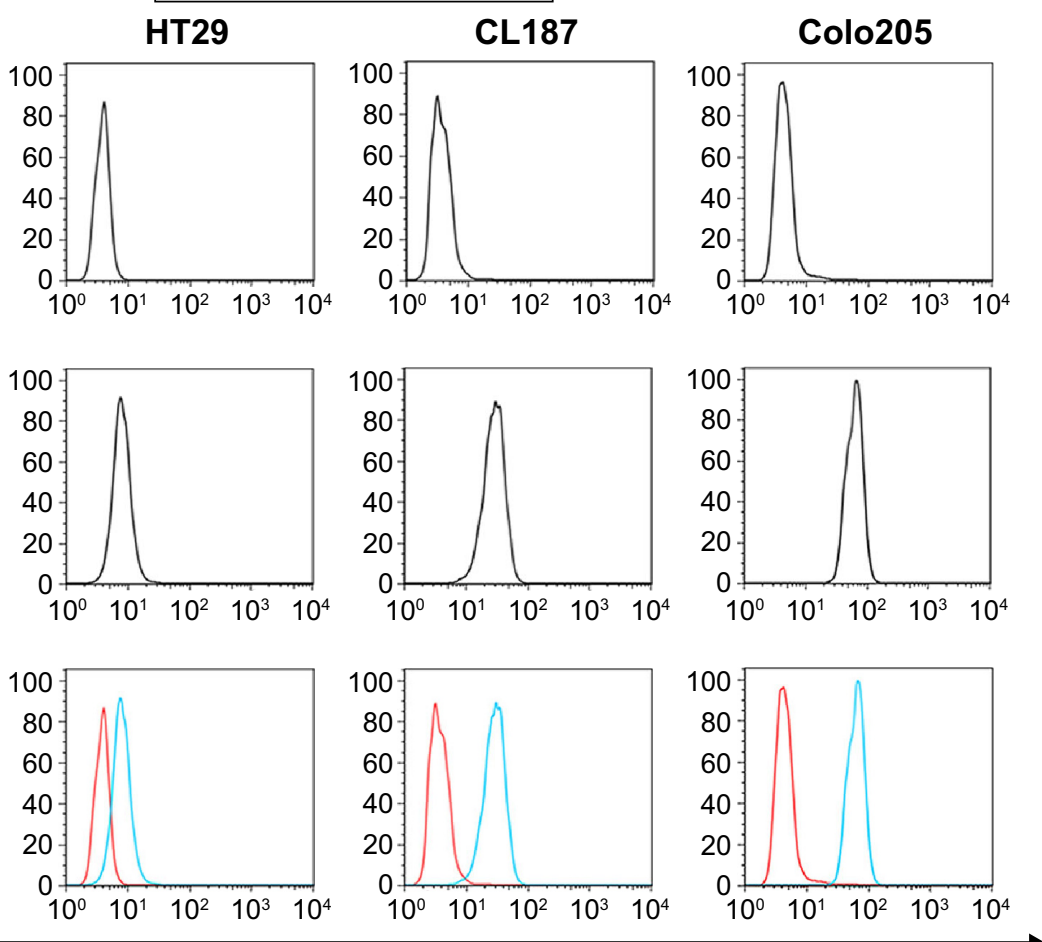

Fluorescence intensity

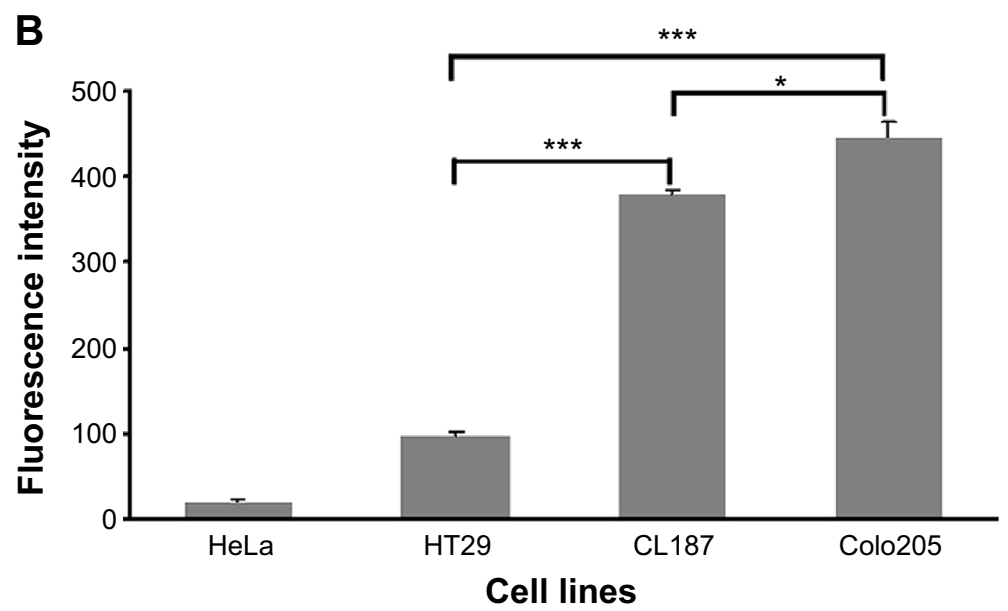

Figure 4 LEA expression in various cell lines using FCM.

Notes: (A) FCM assay. The cells were resuspended in PBS and incubated with ND-I-biotin followed by QD605-SA and subjected to FCM. A blank control was performed by replacing ND-I-biotin with PBS. (B) Graphic representation of mean fluorescence intensity by FCM. Each experiment was performed in triplicate. Data were presented as the mean \pm standard deviation. $* P<0.05$, $* * * P<0.001$.

Abbreviations: LEA, large external antigen; FCM, flow cytometry; QD605-SA, quantum dot-conjugated streptavidin with a $605 \mathrm{~nm}$ emission wavelength; PBS, phosphatebuffered saline. 


\section{Quantitative detection of LEA expression in CRC specimens using QD-IHC}

ND-1-conjugated QD-IHC was used to determine LEA expression in 77 cases of CRC and eight cases of adjacent noncancerous colon tissues. The LEA expression strength was quantitatively classified into four grades $0,1+, 2+$, and 3+. Representative images are shown in Figure 5A, in which positive staining was mainly distributed on cell membranes, with stronger signals on the inner edges of the glandular cavity relative to the outer edges. Based on the grading, the association between LEA expression and clinicopathological parameters is shown in Table 1. The chi-square test and Spearman's correlation analysis showed that there was positive correlation between LEA expression and T-stage $(P=0.030)$. No relationship was found between LEA expression and the other clinicopathological features, including age, sex, tumor size, location, histology, N-stage, and M-stage.

\section{Quantitative detection of LEA expression in CRC specimens using conventional IHC}

The LEA expression levels of the same batch of tissue blocks were detected using conventional IHC. On the basis of staining intensity, LEA expression levels were grouped: $0,1+, 2+$, and $3+$. Representative images are shown in Figure 5B. LEA expression patterns in CRC tissues were similar to those obtained by QD-IHC. Also, as with QD-IHC (Table 2), higher LEA expression levels were correlated with a more advanced T-stage $(P=0.033)$, while there were no significant associations between LEA expression and the other clinicopathological parameters.

\section{Comparison of QD-IHC and conventional IHC in quantitative detection of LEA expression}

As detected using both QD-IHC and conventional IHC, LEA expression levels in CRC tissues were correlated with T-stage, and LEA mainly presented on the cell membrane. Furthermore, the quantitative data on LEA expression were used for the evaluation of the specificities and the sensitivities of QD-IHC and conventional IHC. ROC analysis (Figure 6A) showed that the area under the curve (AUC) of QD-IHC and conventional IHC were 0.890 ( $95 \%$ confidence internal [CI] $0.815-0.964, P=0.000)$ and 0.717 (95\% CI 0.601-0.833, $P=0.045)$, respectively, suggesting that the former possessed increased specificity and sensitivity. The positive rate of

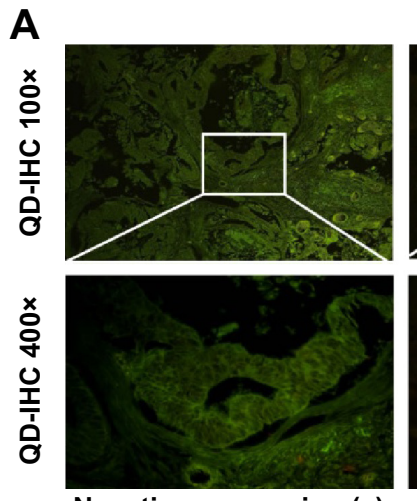

B

Negative expression (-)

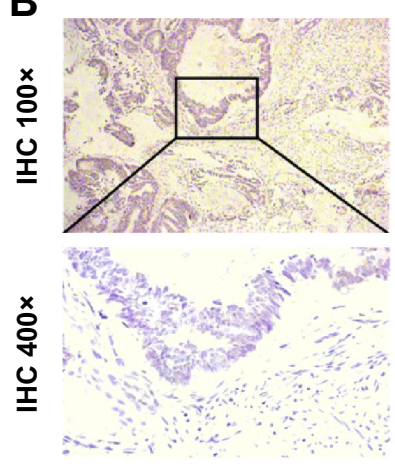

Negative expression (-)
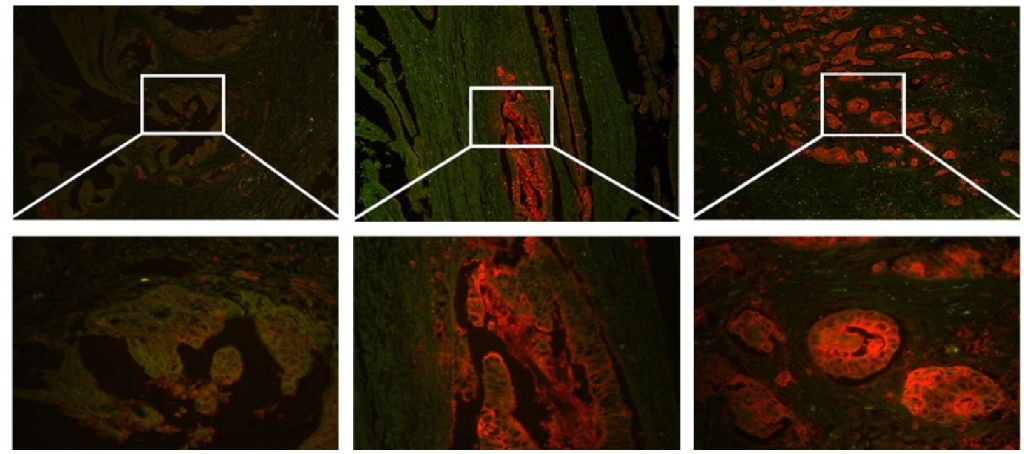

Weak expression (1+)
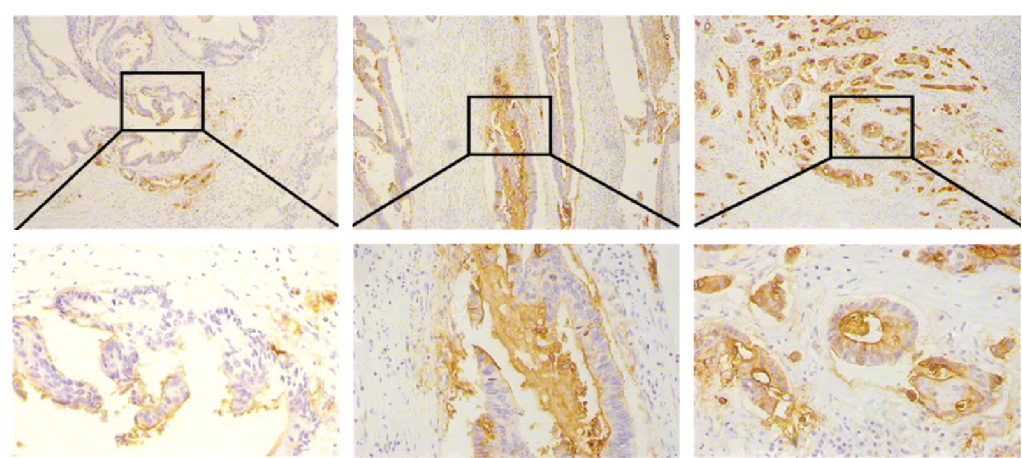

Moderate expression (2+) Strong expression (3+)

Figure 5 Representative images based on LEA expression levels in CRC tissues using (A) QD-IHC and (B) conventional IHC.

Notes: According to the stain intensity, LEA expression levels were classified into four groups, negative expression (-), weak expression (+), moderate expression (2+), and strong expression $(3+)$. A low-power field $(\times 100)$ and a sequentially enlarged field $(\times 400)$ were selected.

Abbreviations: QD-IHC, quantum dot-based immunohistochemistry; IHC, immunohistochemistry; CRC, colorectal cancer; LEA, large external antigen. 
Table I Associations between LEA expression levels detected with QD-IHC and clinicopathological parameters

\begin{tabular}{|c|c|c|c|c|c|c|}
\hline \multirow[t]{3}{*}{ Feature } & \multicolumn{3}{|c|}{ LEA expression, $\mathbf{n}(\%)$} & \multirow{3}{*}{$\frac{\chi^{2} \text {-test }}{P \text {-value }}$} & \multicolumn{2}{|c|}{ Spearman's correlation } \\
\hline & \multirow{2}{*}{$\begin{array}{l}\text { Negative } \\
8(10.4)\end{array}$} & \multirow{2}{*}{$\begin{array}{l}\text { Weak-moderate } \\
43(55.8)\end{array}$} & \multirow{2}{*}{$\begin{array}{l}\text { Strong } \\
26(33.8)\end{array}$} & & \multirow[t]{2}{*}{$r$} & \multirow[t]{2}{*}{$P$-value } \\
\hline & & & & & & \\
\hline \multicolumn{7}{|l|}{ Age (years) } \\
\hline$\leq 60$ & $3(37.5)$ & $16(37.2)$ & $16(6 \mid .5)$ & 0.138 & -0.212 & 0.066 \\
\hline$>60$ & $5(62.5)$ & $27(62.8)$ & $10(38.5)$ & & & \\
\hline \multicolumn{7}{|l|}{ Sex } \\
\hline Female & $3(37.5)$ & $15(34.9)$ & $8(30.8)$ & 0.941 & 0.048 & 0.723 \\
\hline Male & $5(62.5)$ & $28(65.1)$ & $18(69.2)$ & & & \\
\hline \multicolumn{7}{|l|}{ Tumor size } \\
\hline$\leq 5 \mathrm{~cm}$ & $5(62.5)$ & $18(4 \mid .9)$ & I5 (57.7) & 0.360 & -0.030 & 0.590 \\
\hline$>5 \mathrm{~cm}$ & $3(37.5)$ & $25(58.1)$ & II (42.3) & & & \\
\hline \multicolumn{7}{|l|}{ Location } \\
\hline Rectum & $5(62.5)$ & $21(48.8)$ & $13(50.0)$ & 0.844 & 0.040 & 0.784 \\
\hline Colon & $3(37.5)$ & $22(5 \mid .2)$ & $13(50.0)$ & & & \\
\hline \multicolumn{7}{|l|}{ Histology } \\
\hline Adenomatous & 7 (87.5) & $33(76.8)$ & $19(73.0)$ & 0.731 & 0.084 & $0.50 \mathrm{I}$ \\
\hline Mucinous & I (I2.5) & $10(23.2)$ & $7(27.0)$ & & & \\
\hline \multicolumn{7}{|l|}{ T-stage ${ }^{a}$} \\
\hline $\mathrm{T}_{1}, \mathrm{~T}_{2}$ & $3(37.5)$ & $8(18.6)$ & 0 & & & \\
\hline $\mathrm{T}_{3}$ & $4(50.0)$ & $13(30.2)$ & $12(46.2)$ & $0.01 \mathrm{I}^{\mathrm{b}}$ & 0.247 & $0.030^{\mathrm{b}}$ \\
\hline $\mathrm{T}_{4}$ & I (I2.5) & $22(5 \mid .2)$ & $14(53.8)$ & & & \\
\hline \multicolumn{7}{|l|}{ N-stage ${ }^{a}$} \\
\hline $\mathrm{N}_{0}$ & 7 (87.5) & $29(67.4)$ & I5 (57.7) & & & \\
\hline$N_{1}$ & 0 & $8(18.6)$ & $6(23.1)$ & 0.619 & 0.156 & 0.177 \\
\hline $\mathrm{N}_{2}$ & I (I2.5) & $6(14.0)$ & $5(19.2)$ & & & \\
\hline \multicolumn{7}{|l|}{ M-stage } \\
\hline$M_{1}$ & $8(100.0)$ & $40(93.0)$ & $25(96.2)$ & 1.000 & -0.004 & 1.000 \\
\hline$M_{2}$ & 0 & $3(7.0)$ & I (3.8) & & & \\
\hline
\end{tabular}

Notes: a According to the TNM Classification of Malignant Tumors. ${ }^{b} P<0.05$ was considered to indicate a statistically significant difference.

Abbreviations: T, tumor; N, lymph node; M, metastasis; LEA, large external antigen; QD-IHC, quantum dot-based-immunohistochemistry.

LEA expression determined by QD-IHC (89.6\%) was higher than that determined by conventional IHC (70.1\%) with statistically significant difference $(P=0.003)$. In particular, for the $(1+)$ and $(3+)$ groups, the number of cases identified using QD-IHC and conventional IHC were 18 versus nine and 26 versus 18 (Figure 6B), respectively. Representative differential images are shown in Figure 6C.

\section{Discussion}

Tumor markers play important roles in the early diagnosis of cancer or the evaluation of treatment. It has been reported that LEA is a CRC-specific cell surface antigen and is scarcely expressed in normal colon tissues. ${ }^{8}$ Therefore, it was necessary to investigate the relationship between LEA expression levels and clinical characteristics for the discovery of a new tumor-associated marker. Herein, we used QD-IHC technology to quantitatively analyze the LEA expression level in 85 tissue specimens from CRC patients, among which, all eight cases of adjacent noncancerous colon tissue were LEA-negative, indicating that LEA was expressed with high specificity in CRC tissues. Moreover, the statistical analysis revealed a significant correlation between high LEA expression and a more advanced T-stage $(P<0.05)$, although there were no significant associations with age, sex, tumor size, location, histology, N-stage, or M-stage.

According to the tumor staging criteria of the American Joint Committee on Cancer and the Union for International Cancer Control, the T-stage of a tumor is defined by the depth of tumor invasion and the involvement of the adjacent tissue and organs, denoted as $\mathrm{T}_{1}-\mathrm{T}_{4} \cdot{ }^{34}$ Recently, Inoue et $\mathrm{al}^{35}$ demonstrated that the $\mathrm{T}$-stage was the most significant independent prognostic factor associated with disease-free survival in CRC samples. Another study by Gunderson et $\mathrm{al}^{36}$ reported that CRC patients with $\mathrm{T}_{1}-\mathrm{T}_{2}$ had better prognoses than those with $\mathrm{T}_{3}-\mathrm{T}_{4}$. For the first time, the present study showed that LEA expression levels were positively correlated with T-stage, indicating that LEA had the potential to act as a prognostic factor for predicting CRC survival time.

In addition to QD-IHC, we also used conventional IHC to detect LEA expression in the same CRC specimens. Comparatively, conventional IHC showed detection results consistent with QD-IHC in LEA localization and correlation with clinical 
Table 2 Associations between LEA expression levels detected with conventional IHC and clinicopathological parameters

\begin{tabular}{|c|c|c|c|c|c|c|}
\hline \multirow[t]{3}{*}{ Feature } & \multicolumn{3}{|c|}{ LEA expression/n (\%) } & \multirow{3}{*}{$\frac{\chi^{2} \text {-test }}{P \text {-value }}$} & \multicolumn{2}{|c|}{ Spearman's correlation } \\
\hline & Negative & Weak-moderate & Strong & & $r$ & $P$-value \\
\hline & $23(29.8)$ & $36(46.8)$ & $18(23.4)$ & & & \\
\hline \multicolumn{7}{|l|}{ Age (years) } \\
\hline$\leq 60$ & $10(43.5)$ & $12(33.3)$ & $13(72.2)$ & $0.029^{\mathrm{b}}$ & -0.182 & 0.118 \\
\hline$>60$ & $13(56.5)$ & $24(66.7)$ & $5(27.8)$ & & & \\
\hline \multicolumn{7}{|l|}{ Sex } \\
\hline Female & $7(30.4)$ & $12(33.3)$ & $7(38.9)$ & 0.906 & -0.063 & 0.595 \\
\hline Male & $16(69.6)$ & $24(66.7)$ & II (6I.I) & & & \\
\hline \multicolumn{7}{|l|}{ Tumor size } \\
\hline$\leq 5 \mathrm{~cm}$ & $9(39.1)$ & $20(55.6)$ & $9(50.0)$ & 0.468 & -0.091 & 0.430 \\
\hline$>5 \mathrm{~cm}$ & $14(60.9)$ & $16(45.4)$ & $9(50.0)$ & & & \\
\hline \multicolumn{7}{|l|}{ Location } \\
\hline Rectum & $13(56.5)$ & $18(50.0)$ & $8(44.4)$ & 0.765 & 0.088 & 0.491 \\
\hline Colon & $10(43.5)$ & $18(50.0)$ & $10(55.6)$ & & & \\
\hline \multicolumn{7}{|l|}{ Histology } \\
\hline Adenomatous & $20(87.0)$ & $27(75.0)$ & $12(66.7)$ & 0.289 & 0.177 & 0.125 \\
\hline Mucinous & $3(13.0)$ & $9(25.0)$ & $6(33.3)$ & & & \\
\hline \multicolumn{7}{|l|}{ T-stage ${ }^{a}$} \\
\hline $\mathrm{T}_{1}, \mathrm{~T}_{2}$ & $4(17.4)$ & $7(19.4)$ & 0 & & & \\
\hline $\mathrm{T}_{3}$ & $12(52.2)$ & $10(27.8)$ & 7 (38.9) & 0.073 & 0.244 & $0.033^{b}$ \\
\hline $\mathrm{T}_{4}$ & $7(30.4)$ & $19(52.8)$ & II (6I.I) & & & \\
\hline \multicolumn{7}{|l|}{ N-stage ${ }^{a}$} \\
\hline $\mathrm{N}_{0}$ & I5 (65.2) & $25(69.4)$ & II (6I.I) & & & \\
\hline$N_{1}$ & $4(17.4)$ & $6(16.7)$ & $4(22.2)$ & 0.968 & 0.017 & 0.889 \\
\hline $\mathrm{N}_{2}$ & $4(17.4)$ & $5(13.9)$ & $3(16.7)$ & & & \\
\hline \multicolumn{7}{|l|}{ M-stage } \\
\hline$M_{1}$ & $22(95.7)$ & $34(94.4)$ & 17 (94.4) & 1.000 & 0.021 & 0.971 \\
\hline$M_{2}$ & I (4.3) & $2(5.6)$ & I (5.6) & & & \\
\hline
\end{tabular}

Notes: ${ }^{a}$ According to the TNM Classification of Malignant Tumors. ${ }^{b} P<0.05$ was considered to indicate a statistically significant difference.

Abbreviations: T, tumor; N, lymph node; M, metastasis; IHC, immunohistochemistry; LEA, large external antigen.

parameters. Nevertheless, it is worth noting that QD-IHC is superior to conventional IHC in several other aspects. ROC curves used to evaluate specificity and sensitivity displayed higher AUC values with QD-IHC (0.890) relative to those with conventional IHC (0.717). Because QD-IHC and conventional IHC possess the same LEA detection specificity based on the detection of all eight cases of adjacent noncancerous colon tissue as LEA-negative by both methods, the higher AUC value for QD-IHC implies a better detection sensitivity compared with conventional IHC. Its excellent sensitivity resulted in an $89.6 \%$ positive rate for LEA expression in 77 CRC specimens, surpassing the $70.1 \%$ obtained with conventional IHC. The increased positive rate occurs in all groups, especially in groups $1+$ and $3+$ (Figure 6B): specimen 1 harbored LEA expression detectable with QD-IHC but not with conventional IHC, and specimen 2 was grouped into $3+$ by QD-IHC but $1+$ by conventional IHC (Figure 6C). This finding suggests that QD-IHC can detect true samples with higher sensitivity than conventional IHC, without any influence on specificity.
The high sensitivity of the QD-IHC method is mainly attributed to QDs excellent optical characteristics. First, QDs have high fluorescence intensity, which can be easily detected even in cases of rare target antigen expression. ${ }^{37}$ Second, narrow emission spectra allow QD fluorescent signals to be detected without interference from background fluorescent signals. Third, high photostability of QD probes could offer prolonged time to observe samples and capture images without a negative impact on fluorescence intensity. ${ }^{32}$ These properties confer on QD-IHC the potential to detect low abundance proteins in tissue sections with complicated components.

Apart from the high sensitivity of QD-IHC, many studies have demonstrated that QD-IHC produced better image quality compared with conventional IHC staining. ${ }^{27,28}$ From the QD images of LEA detection, fluorescent signals can be clearly observed and LEA localization on the membrane can be distinguished in high resolution, which favors accurate and automated quantitation of the images, and therefore 
A
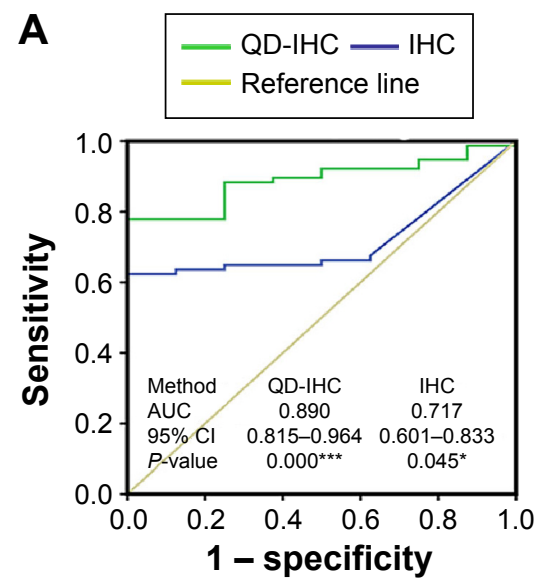

C
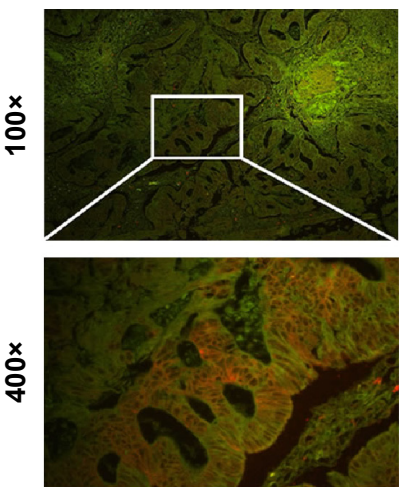

Specimen 1 QD-IHC weak expression (1+)
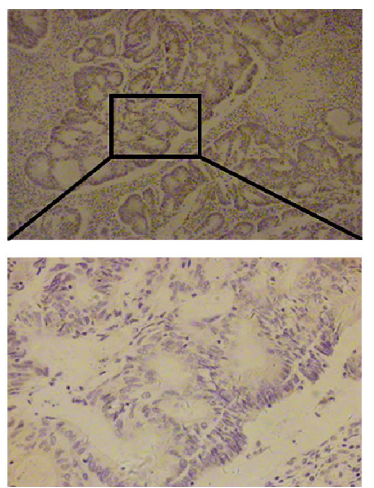

Specimen $1 \mathrm{IHC}$ negative expression (-)
B

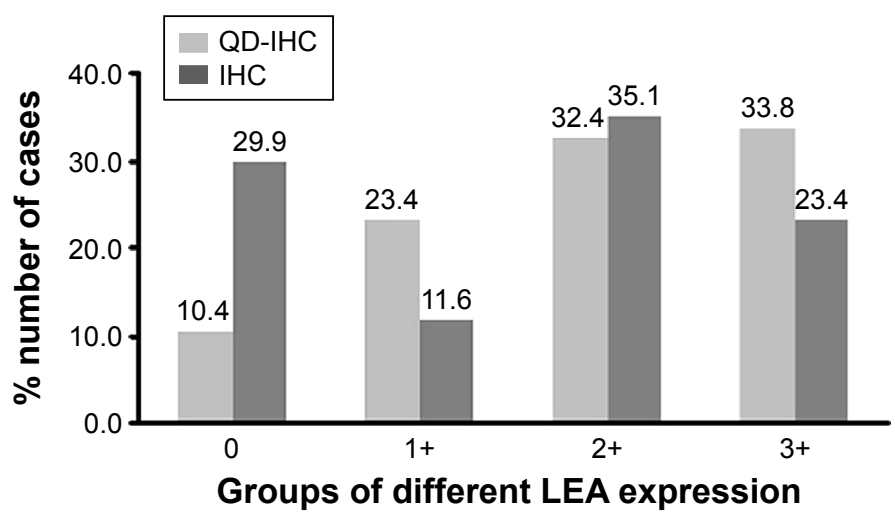

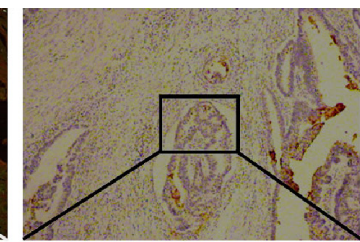

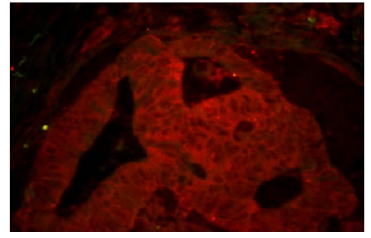

Specimen 2 QD-IHC strong expression (3+)

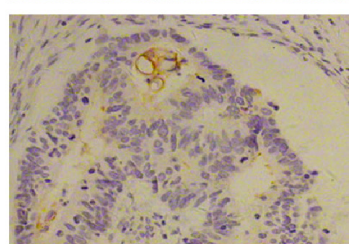

Specimen 2 IHC weak expression (1+)

Figure 6 Comparison of QD-IHC and conventional IHC in detection of LEA expression levels.

Notes: (A) Specificity and sensitivity comparison. LEA expression data from 85 CRC specimens were analyzed by ROC analysis. (B) LEA-positive rate analysis of different expression groups detected using QD-IHC and conventional IHC. (C) The imaging-intensity comparison between QD-IHC and conventional IHC for the same specimens. A low-power field $(\times 100)$ and sequentially enlarged field $(\times 400)$ were selected. $* P<0.05$, $* * * P<0.001$

Abbreviations: QD-IHC, quantum dot-based immunohistochemistry; IHC, immunohistochemistry; CRC, colorectal cancer; LEA, large external antigen; ROC, receiver operating characteristic; AUC, area under the curve; $\mathrm{Cl}$, confidence interval.

avoids possible false-positive error. In this way, the fluorescent intensity of each sample could be analyzed using uniform standards, resulting in more objective and reliable results. In contrast, the stain intensity of conventional IHC is subject to variations in the deposition of chromogens, which lead to wide variations in results interpretation and poor repeatability. In another study, we detected LEA expression in a tissue array of $90 \mathrm{CRC}$ cases and paired adjacent noncancerous colon tissue using the same QD-IHC approach (data not shown), producing data in agreement with the present study, indicating that QD-IHC technology possesses excellent repeatability. Based on these advantages, QD-IHC has the potential to replace conventional IHC and become a more applicable IHC technology.

Currently, most research focuses on developing QD-IHC to evaluate the clinical significance of tumor-associated markers using tumor tissue sections obtained from biopsies or surgeries. Until now, there have been few reports on the detection of living cells or single cells derived noninvasively. The most frequently utilized quantitative detection technology for marker analysis in living cells is FCM. However, the requirements for at least 10,000 cells per analysis and special equipment hinder its application for the detection of rare tumor cells in noninvasively obtained clinical materials, such as circulating blood and ascites. Recent studies reveal CTCs in patient blood are of important diagnostic value, and in particular, the CTCs expressing specific markers might predict tumor metastasis and help monitor clinical treatment response. ${ }^{38,39}$ Nevertheless, only a few CTCs present in $10 \mathrm{~mL}$ of blood results in the inability to detect CTCs using FCM. Based on the high detection efficiency of QDs, we developed the QD-ICC method combined with imaging quantitative analysis for the analysis of LEA expression levels in different CRC cell lines. Quantified with 
this method, Colo205 cells were demonstrated to possess the highest LEA expression level, followed by CL187 and HT29 cells. According to known reports, Colo205 cells are derived from a patient with Dukes' type D, ${ }^{40}$ CL187 cells are from a patient with Dukes' type B, ${ }^{41}$ and HT29 cells are from a well-differentiated grade I tumor (equivalent to Dukes' type A). ${ }^{42}$ This shows that the cell-based QD probe method can reveal the association between LEA expression and tumor characteristics, and remain in agreement with the tissue-based QD method. Furthermore, although nearly identical LEA expression correlation is confirmed using FCM, the cell-based QD probe method offers advantages over FCM, including the observation of cell images, analysis of marker localization, and understanding of tumor heterogeneity. All of these observations indicate that the cell-based QD probe method could be used to detect low abundance cells, such as CTCs, for the purpose of guiding clinical practice.

Cancer is a multistep process characterized by various molecular changes, including expression of tumor-associated markers. Furthermore, most tumor tissues possess high heterogeneity. Hence, combinatorial detection of multirelated tumor markers would increase accuracy and efficiency in clinical diagnosis and treatment. ${ }^{43,44}$ QDs' excellent optical characteristics make it a good alternative for multidetection. ${ }^{45,46}$ With their narrow and symmetrical emission spectra, individual QD signals could be resolved in multiplex labeling. With broad absorption spectra, multiplex QD signals could be excited by a single wavelength without disturbance from different excitation light. Yuan et $\mathrm{al}^{47}$ reported that the combination of $\mathrm{Ki}-67$ and cytokeratin increased the prognostic value of Ki-67 for breast cancer recurrence. Our previous study has showed that LEA is a CRC-related marker, distinct from CEA in chemical and biological properties. ${ }^{8}$ Therefore, it is possible to simultaneously detect LEA, CEA, as well as other CRCrelated markers, using QD-based technology, which would improve their clinical value.

\section{Conclusion}

Using QD-IHC and conventional IHC, we quantitatively analyzed the LEA expression levels in 85 tissue samples from patients with CRC. Both methods demonstrated that LEA is specifically expressed in CRC and that higher LEA expression is associated with a more advanced T-stage, indicating that LEA has the potential to serve as a valuable prognostic tool for CRC. Compared with conventional IHC, QD-IHC possessed several obvious advantages in the quantitative measure of protein marker expression, including higher sensitivity, less human interference, simpler operation, and increased ability for simultaneous multifactor analysis, which would result in more accurate clinical evaluations. Therefore, QD-IHC could be a substitute for conventional IHC in clinical applications. Unlike the majority of other studies that primarily focus on marker detection in tissue sections using QD probes, we developed QD-ICC combined with imaging quantitative analysis for the detection of LEA expression in living cells and achieved results in agreement with those generated using FCM, suggesting that this method is an ideal tool for noninvasive molecular access to rare CTCs and providing the rationale for expanding the application of QD probes to clinical practice.

\section{Acknowledgments}

The study was supported by the grants from the National Natural Science Foundation of China (Grant No 21375149) and Shenyang Science and Technology Bureau (Grant No F13-221-9-29) and Program for Changjiang Scholars and Innovative Research Team in University of Ministry of Education of China (IRT13101).

\section{Disclosure}

The authors report no conflicts of interest in this work.

\section{References}

1. Siegel R, Desantis C, Jemal A. Colorectal cancer statistics, 2014. CA Cancer J Clin. 2014;64(2):104-117.

2. Quere P, Facy O, Manfredi S, et al. Epidemiology, management, and survival of peritoneal carcinomatosis from colorectal cancer: a population-based study. Dis Colon Rectum. 2015;58(8):743-752.

3. Brenner H, Kloor M, Pox CP. Colorectal cancer. Lancet. 2014; 383(9927):1490-1502.

4. Wu L, Qu X. Cancer biomarker detection: recent achievements and challenges. Chem Soc Rev. 2015;44(10):2963-2997.

5. Duffy MJ, Lamerz R, Haglund C, et al. Tumor markers in colorectal cancer, gastric cancer and gastrointestinal stromal cancers: European group on tumor markers 2014 guidelines update. Int J Cancer. 2014;134(11): 2513-2522.

6. Van Cutsem E, Köhne CH, Hitre E, et al. Cetuximab and chemotherapy as initial treatment for metastatic colorectal cancer. NEngl J Med. 2009; 360(14):1408-1417.

7. Thomas DS, Fourkala EO, Apostolidou S, et al. Evaluation of serum CEA, CYFRA21-1 and CA125 for the early detection of colorectal cancer using longitudinal preclinical samples. Br J Cancer. 2015;113(2):268-274.

8. Bleday R, Song J, Walker ES, et al. Characterization of a new monoclonal antibody to a cell surface antigen on colorectal cancer and fetal gut tissues. Cancer. 1986;57(3):433-440.

9. Feng H, Song JD. The study of colorectal carcinoma associated antigen LEA in clinical pathological diagnosis. Chinese J Cancer Res. 2002; 14(1):69-72.

10. Han SX, Wang J, Wang LJ, et al. The role of RCAS1 as a biomarker in diagnosing $\mathrm{CRC}$ and monitoring tumor recurrence and metastasis. Tumour Biol. 2014;35(6):6149-6157.

11. Walker RA. Quantification of immunohistochemistry-issues concerning methods, utility and semiquantitative assessment I. Histopathology. 2006; 49(4):406-410.

12. Ermert L, Hocke AC, Duncker HR, Seeger W, Ermert M. Comparison of different detection methods in quantitative microdensitometry. Am J Pathol. 2001;158(2):407-417. 
13. Taylor CR, Levenson RM. Quantification of immunohistochemistryissues concerning methods, utility and semiquantitative assessment II. Histopathology. 2006;49(4):411-424.

14. Torlakovic EE, Nielsen S, Vyberg M, Taylor CR. Getting controls under control: the time is now for immunohistochemistry. J Clin Pathol. 2015; 68(11):879-882.

15. Warford A, Akbar H, Riberio D. Antigen retrieval, blocking, detection and visualisation systems in immunohistochemistry: a review and practical evaluation of tyramide and rolling circle amplification systems. Methods. 2014;70(1):28-33.

16. Bruchez M, Moronne M, Gin P, Weiss S, Alivisatos AP. Semiconductor nanocrystals as fluorescent biological labels. Science. 1998; 281(5385):2013-2016.

17. Chan WC, Nie S. Quantum dot bioconjugates for ultrasensitive nonisotopic detection. Science. 1998;281(5385):2016-2018.

18. Rizvi SB, Rouhi S, Taniguchi S, et al. Near-infrared quantum dots for HER2 localization and imaging of cancer cells. Int J Nanomedicine. 2014; 9:1323-1337.

19. Ruan J, Song H, Qian Q, et al. HER2 monoclonal antibody conjugated RNase-A-associated CdTe quantum dots for targeted imaging and therapy of gastric cancer. Biomaterials. 2012;33(29):7093-7102.

20. Li WM, Bing T, Wei JY, Chen ZZ, Shangguan DH, Fang J. Cell-SELEXbased selection of aptamers that recognize distinct targets on metastatic colorectal cancer cells. Biomaterials. 2014;35(25):6998-7007.

21. Lin Z, Ma Q, Fei X, Zhang H, Su X. A novel aptamer functionalized CuInS2 quantum dots probe for daunorubicin sensing and near infrared imaging of prostate cancer cells. Anal Chim Acta. 2014;818:54-60.

22. East DA, Mulvihill DP, Todd M, Bruce IJ. QD-antibody conjugates via carbodiimide-mediated coupling: a detailed study of the variables involved and a possible new mechanism for the coupling reaction under basic aqueous conditions. Langmuir. 2011;27(22):13888-13896.

23. Esteve-Turrillas FA, Abad-Fuentes A. Applications of quantum dots as probes in immunosensing of small-sized analytes. Biosens Bioelectron. 2013;41:12-29.

24. Cheng X, Hinde E, Owen DM, et al. Enhancing quantum dots for bioimaging using advanced surface chemistry and advanced optical microscopy: application to silicon quantum dots (SiQDs). Adv Mater. 2015;27(40):6144-6150.

25. Chen $\mathrm{H}$, Wang Z, Zong S, et al. A graphene quantum dot-based FRET system for nuclear-targeted and real-time monitoring of drug delivery. Nanoscale. 2015;7(37):15477-15486.

26. Chen H, Xue J, Zhang Y, Zhu X, Gao J, Yu B. Comparison of quantum dots immunofluorescence histochemistry and conventional immunohistochemistry for the detection of caveolin-1 and PCNA in the lung cancer tissue microarray. J Mol Histol. 2009;40(4):261-268.

27. Sun JZ, Chen C, Jiang G, Tian WQ, Li Y, Sun SR. Quantum dotbased immunofluorescent imaging of Ki67 and identification of prognostic value in HER2-positive (non-luminal) breast cancer. Int $J$ Nanomedicine. 2014;9:1339-1346.

28. Yang XQ, Chen C, Peng CW, et al. Quantum dot-based quantitative immunofluorescence detection and spectrum analysis of epidermal growth factor receptor in breast cancer tissue arrays. Int J Nanomedicine. 2011;6:2265-2273.

29. Ghazani AA, Lee JA, Klostranec J, et al. High throughput quantification of protein expression of cancer antigens in tissue microarray using quantum dot nanocrystals. Nano Lett. 2006;6(12):2881-2886.
30. Tholouli E, Sweeney E, Barrow E, Clay V, Hoyland JA, Byers RJ. Quantum dots light up pathology. J Pathol. 2008;216(3):275-285.

31. Ruan Y, Yu W, Cheng F, Zhang X, Larré S. Detection of prostate stem cell antigen expression in human prostate cancer using quantumdot-based technology. Sensors (Basel). 2012;12(5):5461-5470.

32. Chen C, Peng J, Xia HS, et al. Quantum dots-based immunofluorescence technology for the quantitative determination of HER2 expression in breast cancer. Biomaterials. 2009;30(15):2912-2918.

33. Mateo J, Gerlinger M, Rodrigues DN, de Bono JS. The promise of circulating tumor cell analysis in cancer management. Genome Biol. 2014; 15(8):448-458.

34. Edge SB, Byrd DR, Compton CC, Fritz AG, Greene FL, Trotti A, editors. AJCC Cancer Staging Manual. 7th ed. New York: Springer; 2010.

35. Inoue $Y$, Saigusa $S$, Iwata $T$, et al. The prognostic value of KRAS mutations in patients with colorectal cancer. Oncol Rep. 2012;28(5):1579-1584.

36. Gunderson LL, Jessup JM, Sargent DJ, Greene FL, Stewart A. Revised tumor and node categorization for rectal cancer based on surveillance, epidemiology, and end results and rectal pooled analysis outcomes. J Clin Oncol. 2010;28(2):256-263.

37. Howarth M, Takao K, Hayashi Y, Ting AY. Targeting quantum dots to surface proteins in living cells with biotin ligase. Proc Natl Acad Sci USA. 2005;102(21):7583-7588.

38. Horn P, Jakobsen EH, Madsen JS, Brandslund I. New approach for interpreting changes in circulating tumour cells (CTC) for evaluation of treatment effect in metastatic breast cancer. Transl Oncol. 2014;7(6): 694-701.

39. Thorsteinsson M, Jess P. The clinical significance of circulating tumor cells in non-metastatic colorectal cancer-a review. Eur J Surg Oncol. 2011;37(6):459-465.

40. Semple TU, Quinn LA, Woods LK, Moore GE. Tumor and lymphoid cell lines from a patient with carcinoma of the colon for a cytotoxicity model. Cancer Res. 1978;38(5):1345-1355.

41. Tom BH, Rutzky LP, Jakstys MM, Oyasu R, Kaye CI, Kahan BD. Human colonic adenocarcinoma cells I. Establishment and description of a new line. In Vitro. 1976;12(3):180-191.

42. Didier ES, Rogers LB, Orenstein JM, et al. Characterization of Encephalitozoon (Septata) intestinalis isolates cultured from nasal mucosa and bronchoalveolar lavage fluids of two AIDS patients. J Eukaryot Microbiol. 1996;43(1):34-43.

43. Gorelik E, Landsittel DP, Marrangoni AM, et al. Multiplexed immuno bead-based cytokine profiling for early detection of ovarian cancer. Cancer Epidemiol Biomarkers Prev. 2005;14(4):981-987.

44. Tampellini M, Ottone A, Alabiso I, et al. The prognostic role of baseline CEA and CA 19-9 values and their time-dependent variations in advanced colorectal cancer patients submitted to first-line therapy. Tumour Biol. 2015;36(3):1519-1527.

45. Xing Y, Chaudry Q, Shen C, et al. Bioconjugated quantum dots for multiplexed and quantitative immunohistochemistry. Nat Protoc. 2007; 2(5):1152-1165.

46. Tian J, Zhou L, Zhao Y, Wang Y, Peng Y, Zhao S. Multiplexed detection of tumor markers with multicolor quantum dots based on fluorescence polarization immunoassay. Talanta. 2012;92:72-77.

47. Yuan JP, Wang LW, Qu AP, et al. Quantum dots-based quantitative and in situ multiple imaging on Ki67 and cytokeratin to improve Ki67 assessment in breast cancer. PLoS One. 2015;10(4):e0122734.
International Journal of Nanomedicine

\section{Publish your work in this journal}

The International Journal of Nanomedicine is an international, peerreviewed journal focusing on the application of nanotechnology in diagnostics, therapeutics, and drug delivery systems throughout the biomedical field. This journal is indexed on PubMed Central, MedLine, CAS, SciSearch ${ }^{\circledR}$, Current Contents ${ } /$ Clinical Medicine,

\section{Dovepress}

Journal Citation Reports/Science Edition, EMBase, Scopus and the Elsevier Bibliographic databases. The manuscript management system is completely online and includes a very quick and fair peer-review system, which is all easy to use. Visit http://www.dovepress.com/ testimonials.php to read real quotes from published authors. 